\title{
BIOMASSA VERDE dE PLANTAS COMO ADUBO DE COBERTURA EM CULTIVO ORGÂNICO DE REPOLHO
}

\author{
Luiz Fernando Favarato ${ }^{1}$, Jacimar Luiz de Souza ${ }^{2}$, Rogério Carvalho Guarçoni ${ }^{3}$, Victor Almeida Pereira ${ }^{4}$
}

\begin{abstract}
RESUMO - O objetivo deste trabalho foi avaliar o potencial de uso da biomassa da parte aérea de leucena e mamona como adubação de cobertura, sobre o desenvolvimento do repolho e os atributos do solo em sistema orgânico de produção. Foram implantados dois experimentos no ano de 2011 , com leucena e mamona, avaliando-se cinco espessuras de biomassa $(0,1,2,3$ e $4 \mathrm{~cm})$ como cobertura no entorno das plantas de repolho, aplicadas aos 15 dias após o transplantio. Os resultados comprovaram efeitos significativos destas formas de adubação sobre o desenvolvimento inicial das plantas de repolho e sobre os atributos do solo, comprovando eficiência no fornecimento de nitrogênio para esta cultura. Não foram verificados ajustes significativos para os modelos de regressão sobre os atributos do solo para as diferentes espessuras de aplicação das biomassas, à exceção do teor de potássio, que foi favorecido com o aumento das quantidades aplicadas.
\end{abstract}

Palavras-chave: adubação verde, agricultura orgânica, Brassica oleracea, Leucaena leucocephala, Ricinus communis.

\section{FRESH BIOMASS OF PLANTS AS COVER FERTILIZER FOR ORGANIC CULTIVATION OF CABBAGE}

\begin{abstract}
The objective of this study was to evaluate the potential of biomass of leucaena and castor as cover fertilizer, on development of cabbage and soil characteristics in an organic system of production. Two experiments were conducted in 2011, with leucaena and castor, evaluating five biomass thicknesses ( 0 , 1, 2, 3 e $4 \mathrm{~cm}$ ) as cover in around cabbage plants, applied 15 days after planting. The results showed significant effects of forms fertilization on initial development of cabbage plants and on soil properties, proving efficiency in providing nitrogen to the crop. There were found no significant adjustments to the regression models on soil properties for different thicknesses of application of biomass, except for potassium content, which was favored with the increase in the amounts applied.
\end{abstract}

Keywords: Brassica oleracea, green manure, Leucaena leucocephala, organic agriculture, Ricinus communis.

\footnotetext{
${ }^{1}$ Engenheiro Agrônomo, Doutor, Centro Regional Centro-Serrano, Instituto Capixaba de Pesquisa, Assistência Técnica e Extensão Rural, Br 262, Km 94, 29375-000 Venda Nova do Imigrante, Espírito Santo, Brasil. 1ffavarato@gmail.com (Autor para correspondência)

${ }^{2}$ Engenheiro Agrônomo, Doutor, Centro Regional Centro-Serrano, Instituto Capixaba de Pesquisa, Assistência Técnica e Extensão Rural, Br 262, Km 94, 29375-000 Venda Nova do Imigrante, Espírito Santo, Brasil. jacimarsouza@yahoo.com.br

${ }^{3}$ Engenheiro Agrícola, Doutor, Centro Regional Centro-Serrano, Instituto Capixaba de Pesquisa, Assistência Técnica e Extensão Rural, Br 262, Km 94, 29375-000 Venda Nova do Imigrante, Espírito Santo, Brasil. rogerio.guarconi@ incaper.es.gov.br

${ }^{4}$ Engenheiro Agrônomo, Prefeitura de Irupi, 151, 29398-000, Irupi, Espírito Santo, Brasil. victorap1@hotmail.com
} 


\section{INTRODUÇÃO}

A utilização de biomassas da parte aérea de plantas como prática cultural de cobertura morta do solo é utilizada na olericultura como prática conservacionista e para ganhos de produção, principalmente no que diz respeito ao aumento da matéria orgânica, retenção de água e melhoria nos atributos químicos do solo (Oliveira et al., 2008).

Entre as espécies utilizadas para cobertura morta de solo, destacam-se as leguminosas por fixarem nitrogênio $(\mathrm{N})$ atmosférico por associação com bactérias fixadoras de $\mathrm{N}$, aumentando o aporte deste elemento no sistema, de forma mais ágil, pois a decomposição de sua palhada é rápida, quando fragmentada e depositada na superfície do solo, com liberação de nutrientes e favorecimento do desempenho agronômico das culturas (Aita \& Giacomini, 2003).

Jama et al. (2000) relatam várias bibliografias sobre o uso de margaridão (Tithonia diversifolia) como adubo verde de cobertura, na forma de corte e aplicação sobre o solo, na região oeste do Quênia, onde há grande abundância e alta produção de biomassa desta espécie. A composição média verificada para esta planta foi $3,5 \%$ de $\mathrm{N}, 0,37 \%$ de fósforo (P) e $4,1 \%$ de potássio (K), comprovando seu potencial de uso como fornecedora de nutrientes como adubo de cobertura. Segundo os autores, há relatos comprovados de melhoria na fertilidade do solo e no desenvolvimento de várias culturas. O uso de 5,0 $\mathrm{t} \mathrm{ha}^{-1}$ de matéria seca reduziu a adsorção de fósforo e aumentou a biomassa microbiana no solo. Observou-se também que o uso do margaridão foi mais rentável em culturas de maior retorno econômico como as hortaliças, do que com milho, devido aos custos de corte, transporte e aplicação da biomassa no campo.

Aguyoh et al. (2010) relataram que o declínio da produtividade da melancia no Quênia é devido ao esgotamento do nitrogênio e da matéria orgânica do solo. Por isso, avaliaram o uso de diversas quantidades de biomassa verde de Tithonia diversifolia, equivalentes a 1,8 t.ha ${ }^{-1}, 3,6$ t.ha ${ }^{-1}$ e 5,4 tha ${ }^{-1}$ de matéria seca, como adubo de cobertura para esta cultura. A dose mais alta de 5,4 tha ${ }^{-1}$ aumentou significativamente a produção total e comercial de frutos, o número de frutos e o peso médio. Os acréscimos na produção total variaram de $25 \%$ a $31 \%$, com melhorias também no teor de açúcares dos frutos.

Baggio \& Soares (2002) avaliaram a resposta do morangueiro à aplicação de biomassa verde triturada de timbó (Ateleia glazioveana Baillon), que apresentava $3,5 \%$ de $\mathrm{N}$ na matéria seca das folhas e $1,5 \%$ nos ramos finos. A biomassa foi incorporada ao solo do canteiro 20 dias antes do plantio das mudas, na base de 1,8 kg.m${ }^{2}$, equivalente a $200 \mathrm{~kg}$ de $\mathrm{N}$ por ha. A produção total de 383,35 g por planta nos morangueiros adubados com timbó foi $18,45 \%$ superior às $323,63 \mathrm{~g}$ por planta, obtida na adubação orgânica convencional com esterco e MB- $4^{\circledR}$. Também não foram detectados quaisquer problemas de fitotoxicidade ou fitossanidade da biomassa de timbó sobre a cultura.

Além do ganho produtivo das culturas, o aporte de biomassa triturada de leguminosas pode alterar os atributos químicos e físicos do solo, conforme relatado por Barreto $\&$ Fernandes (2001). Cultivando mandioca em alamedas de gliricídia e leucena, esses autores comprovaram melhorias no potencial hidrogeniônico $(\mathrm{pH})$, cálcio $(\mathrm{Ca})$ e magnésio $(\mathrm{Mg})$, densidade e macroporosidade, mas não detectaram diferenças na matéria orgânica e capacidade de troca catiônica (CTC), após três anos de manejo.

O desempenho produtivo de muitas hortaliças em sistema orgânico de cultivo tem sido limitado pelo fornecimento insuficiente do nitrogênio, tanto pela baixa adoção da adubação verde, como pelo baixo uso de fontes de resíduos orgânicos ricos em nitrogênio para complementar a nutrição das plantas. Assim, o objetivo deste trabalho foi avaliar os efeitos da adubação em cobertura com biomassa verde triturada de leucena (Leucaena leucocephala) e mamona (Ricinus communis), para o desenvolvimento do repolho e suas interferências nas características do solo.

\section{MATERIALE MÉTODOS}

Este trabalho foi executado na Unidade de Referência em Agroecologia do Incaper, município de Domingos Martins-ES, no período de maio a julho de 2011, por meio de dois experimentos, sendo um com resíduos triturados de leucena e outro com resíduos triturados de mamona, como adubos de cobertura, utilizandose mudas de repolho da variedade 'chato de quintal', transplantadas aos 25 dias após semeio.

Os resíduos verdes de leucena utilizados eram constituídos de ramos e folhas obtidos de plantas submetidas a podas 2 a 3 vezes ao ano, com comprimento de hastes variando de 1,5 a $2,5 \mathrm{~m}$. Os resíduos verdes de mamona constituídos de hastes tenras, talos, folhas e bagas, retirados das extremidades das plantas. A trituração 
de ambos resíduos foi feita em um triturador vertical, regulado para espessura de corte de $5 \mathrm{~mm}$. A biomassa foi adicionada como adubação em cobertura nos vasos com repolho, aos 15 dias após o transplantio das mudas.

As composições médias das biomassas trituradas confirmaram teor de nitrogênio, com 3,4\% para a leucena e $3,5 \%$ para a mamona. A biomassa verde de leucena apresentou teor médio de $27 \%$ de matéria seca, sendo esta constituída de: matéria orgânica $(94 \%) ; \mathrm{pH}(5,8)$; $\mathrm{N}(3,4 \%) ; \mathrm{P}(0,3 \%) ; \mathrm{K}(2,0 \%) ; \mathrm{Ca}(1,3 \%) ; \mathrm{Mg}(0,2 \%)$; $\mathrm{S}(0,2 \%) ; \mathrm{Zn}\left(28 \mathrm{mg} \cdot \mathrm{kg}^{-1}\right) ; \mathrm{Fe}\left(153 \mathrm{mg} \cdot \mathrm{kg}^{-1}\right) ; \mathrm{Mn}(41$ mg. $\left.\mathrm{kg}^{-1}\right) ; \mathrm{Cu}\left(6 \mathrm{mg} \cdot \mathrm{kg}^{-1}\right)$ e B $\left(30 \mathrm{mg} \cdot \mathrm{kg}^{-1}\right)$. A biomassa verde de mamona apresentou teor médio de $21 \%$ de matéria seca, sendo esta constituída de: matéria orgânica (92\%); pH (5,3); N (3,5\%); P (0,4\%); K (2,2\%); Ca (1,5\%); $\mathrm{Mg}(0,2 \%) ; \mathrm{S}(0,2 \%) ; \mathrm{Zn}\left(42 \mathrm{mg} \cdot \mathrm{kg}^{-1}\right) ; \mathrm{Fe}$ (189 mg.kg $\left.{ }^{1}\right)$; $\mathrm{Mn}\left(85 \mathrm{mg} \cdot \mathrm{kg}^{-1}\right)$; Cu (9 mg. $\left.\mathrm{kg}^{-1}\right)$ e B (27 mg. $\left.\mathrm{kg}^{-1}\right)$.

As unidades experimentais foram compostas de uma planta de repolho, plantada em vasos redondos, com diâmetro de $25 \mathrm{~cm}$ e altura de $20 \mathrm{~cm}$. Estes recipientes foram preenchidos com solo homogeneizado retirada de uma área da unidade experimental de cultivo orgânico. No início e final do experimento foram retiradas amostras simples do solo de cada parcela para caracterização e avaliação do efeito da adubação em cobertura sobre os solos em cada tratamento.

Para o plantio das mudas, não foi adotada adubação de base, devido ao alto nível de fertilidade do solo, advindo de sistema orgânico com grande conteúdo residual de adubos orgânicos utilizados em cultivos anteriores. As adubações em cobertura foram realizadas com resíduos verdes triturados de leucena e mamona, aplicados em quatro espessuras de cobertura no entorno da muda, em toda superfície do vaso, correspondente a uma área de $0,049 \mathrm{~m}^{2}$ por muda. O delineamento experimental de cada experimento foi em blocos casualizados, com cinco repetições, seguindo um esquema de parcelas subdivididas no tempo, com cinco tratamentos nas parcelas e cinco épocas de avaliações nas subparcelas $(0,7,14,21$ e 28 dias $)$.

Os tratamentos do experimento 1, utilizando-se a leucena triturada (com densidade $=252 \mathrm{~kg} \cdot \mathrm{m}^{-3}$, teor de matéria seca $=27 \%$ e teor de $\mathrm{N}=3,4 \%$ ) em cinco espessuras de camada, estão apresentados a seguir, com os correspondentes aportes de volume, biomassa e nitrogênio por hectare: 1) $0 \mathrm{~cm}$ (sem adubação cobertura); 2) $1 \mathrm{~cm}\left(20,4 \mathrm{~m}^{3} \cdot \mathrm{ha}^{-1}\right)=5.141 \mathrm{~kg}$ verde ha-1 $=1.388 \mathrm{~kg}$ seco ha ${ }^{-1}=47 \mathrm{~kg}$ de $\left.\mathrm{N} \mathrm{ha}^{-1} ; 3\right) 2 \mathrm{~cm}\left(40,8 \mathrm{~m}^{3} \cdot \mathrm{ha}^{-1}\right)=$
$10.282 \mathrm{~kg}$ verde ha-1 $=2.776 \mathrm{~kg}$ seco ha-1 $=94 \mathrm{~kg}$ de $\mathrm{N} \mathrm{ha}^{-1}$; 4) $3 \mathrm{~cm}\left(61,2 \mathrm{~m}^{3} \cdot \mathrm{ha}^{-1}\right)=15.423 \mathrm{~kg}$ verde ha $\mathrm{ha}^{-1}$ $=4.164 \mathrm{~kg} \mathrm{seco} \mathrm{ha} \mathrm{h}^{-1}=141 \mathrm{~kg}$ de $\left.\mathrm{N} \mathrm{ha}^{-1} ; 5\right) 4 \mathrm{~cm}(81,6$ $\left.\mathrm{m}^{3} \cdot \mathrm{ha}^{-1}\right)=20.564 \mathrm{~kg}$ verde $\mathrm{ha}^{-1}=5.552 \mathrm{~kg}$ seco ha-1

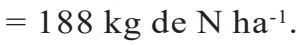

Os tratamentos do experimento 2, utilizando-se a mamona triturada (com densidade $=290 \mathrm{~kg} \cdot \mathrm{m}^{3}$, teor de matéria seca $=21 \%$ e teor de $\mathrm{N}=3,5 \%$ ) em cinco espessuras de camada, estão apresentados a seguir, com os correspondentes aportes de volume, biomassa e nitrogênio por hectare: 1) $0 \mathrm{~cm}$ (sem adubação cobertura); 2) $1 \mathrm{~cm}\left(20,4 \mathrm{~m}^{3} \cdot \mathrm{ha}^{-1}\right)=5.916 \mathrm{~kg}$ verde ha-1 $=1.242 \mathrm{~kg} \mathrm{seco}$ $\mathrm{ha}^{-1}=43 \mathrm{~kg}$ de $\mathrm{N} \mathrm{ha}^{-1}$; 3$) 2 \mathrm{~cm}\left(40,8 \mathrm{~m}^{3} \cdot \mathrm{ha}^{-1}\right)=11.832 \mathrm{~kg}$ verde ha-1 $=2.484 \mathrm{~kg} \mathrm{seco} \mathrm{ha} \mathrm{h}^{-1}=86 \mathrm{~kg} \mathrm{de} \mathrm{N} \mathrm{ha}^{-1}$; 4) $3 \mathrm{~cm}$ $\left(61,2 \mathrm{~m}^{3} \cdot \mathrm{ha}^{-1}\right)=17.748 \mathrm{~kg}$ verde ha-1 $=3.724 \mathrm{~kg} \mathrm{seco} \mathrm{ha}^{-1}$ $\left.=129 \mathrm{~kg} \mathrm{de} \mathrm{Nha}^{-1} ; 5\right) 4 \mathrm{~cm}\left(81,6 \mathrm{~m}^{3} \cdot \mathrm{ha}^{-1}\right)=23.664 \mathrm{~kg}$ verde

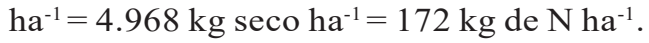

As irrigações dos vasos foram feitas no turno de rega de 2 dias, com volume de água de $200 \mathrm{~mL}$ para todos os tratamentos. Após a adubação de cobertura, as avaliações do vigor (por avaliação visual com escala de notas de 0 a 10 , onde 0 é ausência de crescimento e 10 é crescimento normal) e da altura das plantas (medidas em $\mathrm{cm}$ ), foram realizadas a cada 7 dias. No final dos experimentos, aos 28 dias após a aplicação da adubação em cobertura, foram avaliados o número de folhas e a massa da matéria fresca e seca da parte aérea das plantas de repolho.

Amostras de solo foram coletadas antes e após 28 dias da adubação de cobertura, ou seja, antes e depois, visando avaliar o impacto sobre a fertilidade. Foram determinados, segundo Embrapa (1997), o pH em $\mathrm{H}_{2} \mathrm{O}$ na relação 1:2,5 (solo:água); $\mathrm{P}$ disponível: extrator Mehlich ${ }^{1}$ e determinação por colorimetria; $\mathrm{K}^{+}$: extrator Mehlich ${ }^{1}$ e determinação por espectrofotometria de chama; $\mathrm{Ca}^{+2}$ e $\mathrm{Mg}^{+2}$ : extrator $\mathrm{KCl} 1$ mol.L $\mathrm{L}^{-1}$ e determinação por espectrometria de absorção atômica; $\mathrm{Al}^{+3}$ : extrator $\mathrm{KCl} 1$ mol.L $\mathrm{L}^{-1}$ e determinação por titulometria com $\mathrm{NaOH}$ 0,025 mol. $\mathrm{L}^{-1} ; \mathrm{H}+\mathrm{Al}$ : extrator $\mathrm{Ca}(\mathrm{Oac})_{2} 0,5 \mathrm{~mol} \cdot \mathrm{L}^{-1} \mathrm{a}$ pH 7,0 e matéria orgânica (MO): oxidação de carbono via úmido com dicromato de sódio em meio ácido $\left(\mathrm{H}_{2} \mathrm{SO}_{4}\right)$ (Yeomans \& Breemner, 1988).

Os dados das características vigor e altura foram submetidos à análise de regressão utilizando o desdobramento das interações para estudar o comportamento das épocas de avalição (a cada 7 dias) dentro de cada espessura de camada e vice-versa. Para as características número de folhas, massa da matéria 
fresca e seca da parte aérea das plantas de repolho e para as de fertilidade de solo coletadas aos 28 dias após a adubação de cobertura, os dados foram submetidos às análises de regressão. Os modelos foram testados pelo teste $\mathrm{F}$ e os coeficientes pelo teste $\mathrm{t}$, e as médias das características de adubação de cobertura, antes e depois, foram comparadas utilizando o teste $\mathrm{t}$, empregando-se o programa para análise estatística SAEG (Ribeiro Júnior \& Melo, 2009).

\section{RESULTADOS E DISCUSSÃO}

O número de folhas do repolho foi afetado significativamente de forma linear pelos diferentes aportes de N pela biomassa de leucena (Figura 1A), não atingindo ponto de estabilidade, indicando potencial de resposta com aporte de maiores quantidades de biomassa. Para a mamona, apesar da tendência ter sido similar, o modelo de regressão não foi significativo (Figura 1B).

Moreira et al. (2011), avaliando o crescimento e produção de repolho em função de doses de nitrogênio, também observaram incremento linear do número de folha com o aumento das doses de $\mathrm{N}$ de 0 a $450 \mathrm{~kg}$.ha1, atribuindo este resultado ao efeito promovedor do nitrogênio no crescimento (Ferreira et al., 2002). Ekbladh et al. (2007) também encontraram relação de proporcionalidade entre área foliar e nitrogênio, mostrando relação direta entre expansão da área foliar e absorção de N.

A massa da matéria fresca e seca do repolho elevaramse progressivamente com o aumento do aporte de $\mathrm{N}$ pelas biomassas de leucena e de mamona. Para a leucena, a massa da matéria fresca das plantas de repolho apresentou ajuste significativo ao modelo quadrático, com tendência de estabilização a partir de $226 \mathrm{~kg} \cdot \mathrm{ha}^{-1}$ de N (Figura 1C). Por outro lado, a massa da matéria seca apresentou ajuste significativo ao modelo linear (Figura 1D).

Para a mamona, tanto para a massa da matéria fresca quanto para matéria seca das plantas, o melhor ajuste foi verificado no modelo linear, com o aumento do $\mathrm{N}$ pela biomassa (Figuras 1E e 1F, respectivamente). De forma semelhante ao obtido no presente trabalho, Moreira et al. (2011) observaram que a massa da matéria seca de folhas e caules das plantas de repolho aumentaram de forma linear ao aumento das doses de N. Esses resultados comprovam a importância do nitrogênio no crescimento das plantas de repolho, onde o incremento nas doses de nitrogênio, ao proporcionar maior disponibilidade do nutriente às plantas, estimulou o crescimento do repolho, resultando em maior produção de matéria seca.
$\mathrm{O}$ vigor das plantas foi afetado positivamente pelos tratamentos a partir de 21 dias da adubação em cobertura, comprovando eficiência significativa da biomassa de leucena na nutrição nitrogenada do repolho, com ajuste linear aos 21 dias e ajuste polinomial quadrático aos 28 dias (Figura 1G). A biomassa de mamona apresentou a mesma tendência de efeito, mas não houve ajuste significativo aos modelos. O acompanhamento do vigor das plantas no tempo também confirmou a eficiência da adubação em cobertura com leucena, uma vez que na ausência de adubação e no menor aporte de N (47 kg.ha-1), houve decréscimo linear do vigor até 28 dias. Porém, nas adubações com maior aporte de $\mathrm{N}\left(94,141\right.$ e $\left.188 \mathrm{~kg} \cdot \mathrm{ha}^{-1}\right)$ comprovaramse progressões de vigor no tempo (Figura $1 \mathrm{H}$ ).

As alturas das plantas de repolho não foram afetadas pelas adubações em cobertura com biomassa de leucena e mamona, não havendo relação funcional significativa com as quantidades de biomassa aplicada. A limitação de resposta em altura de plantas a crescentes aportes de $\mathrm{N}$ pelas biomassas pode ser justificada pela característica genética de crescimento da planta de repolho, que no estágio fenológico intermediário apresentam maior crescimento lateral do que vertical.

As médias das características dos atributos químicos dos solos, antes e 28 dias depois da aplicação dos tratamentos em cada experimento, estão apresentadas na Tabela 1. Analisando-se as características antes e depois da aplicação dos tratamentos, verificou-se que o $\mathrm{pH}$ e a capacidade de troca de cátions foram elevados pelos efeitos das biomassas de leucena a partir da espessura de $3 \mathrm{~cm}$ e da mamona a partir da espessura de $2 \mathrm{~cm}$. O maior efeito por ocasião do uso da mamona, iniciando-se com a aplicação de uma camada de $2 \mathrm{~cm}$, se deve aos maiores teores de potássio e cálcio na sua biomassa $(\mathrm{K}=2,2 \% \mathrm{e} \mathrm{Ca}=1,5 \%)$, em relação à leucena $(\mathrm{K}=2,0 \%$ e $\mathrm{Ca}=1,3 \%)$, respectivamente, como indicado nas análises laboratoriais. Reflexo disto, o aporte dos dois tipos de biomassa, a partir da espessura de $2 \mathrm{~cm}$, contribuiu para manter a saturação de bases do solo, que nos tratamentos sem adubação de cobertura e $1 \mathrm{~cm}$, reduziu significativamente ao nível de 5\% de probabilidade. A matéria orgânica do solo não foi afetada pela aplicação das biomassas das plantas (Tabela 1).

Aos 28 dias após a aplicação dos tratamentos, verificou-se um decréscimo significativo de fósforo (P) no solo em todos os tratamentos com leucena e mamona, sendo este fato atribuído ao baixo teor de P na composição dos tecidos destas plantas, associado 

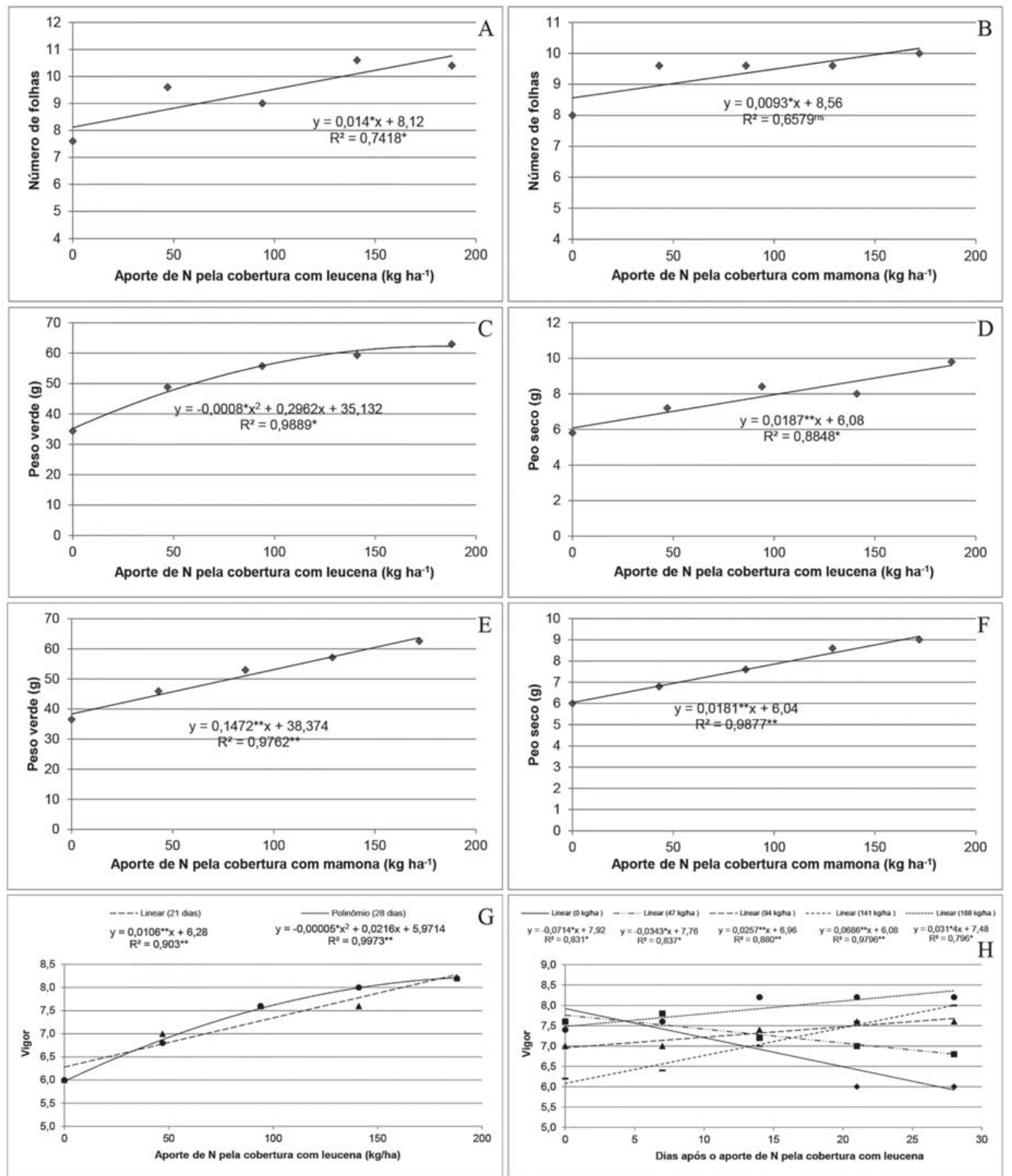

Figura 1 - Número de folhas em função do aporte de N pela biomassa de leucena (A) e mamona (B); Peso verde (C) e seco (D) de plantas de repolho em função do aporte de N pela biomassa de leucena; Peso verde (E) e seco (F) de plantas de repolho em função do aporte de $\mathrm{N}$ pela biomassa de mamona. Vigor de plantas de repolho aos 21 e 28 dias em função do aporte de N (G) e em função do tempo após aplicação $(\mathrm{H})$ da biomassa de leucena. 
à extração deste nutriente pelas plantas de repolho. Por outro lado, por serem plantas com boa composição em potássio $(\mathrm{K})$ e por este nutriente deslocar-se facilmente da biomassa para o solo, o teor de $\mathrm{K}$ foi maior aos 28 dias após a aplicação de 3 e $4 \mathrm{~cm}$ de leucena e após a aplicação de 2, 3 e 4 cm de mamona (Tabela 2). O

Tabela 1 - pH, capacidade de troca de cátions (CTC), saturação de bases (V) e matéria orgânica (MO) do solo, antes e 28 dias após a adubação de cobertura com biomassa de leucena (A) e mamona (B) ${ }^{1}$

\begin{tabular}{|c|c|c|c|c|c|c|c|c|}
\hline \multirow{4}{*}{ Espessura - aporte de $\mathrm{N}$} & \multicolumn{8}{|c|}{ (A) Biomassa de leucena } \\
\hline & \multicolumn{2}{|c|}{$\mathrm{pH}$} & \multicolumn{2}{|c|}{ CTC } & \multicolumn{2}{|c|}{$\mathrm{V}$} & \multicolumn{2}{|c|}{$\mathrm{MO}$} \\
\hline & \multicolumn{2}{|c|}{ (água $1: 2,5$ ) } & \multicolumn{2}{|c|}{$\left(\mathrm{cmol}_{\mathrm{c}} \mathrm{dm}^{-3}\right)$} & \multicolumn{4}{|c|}{$(\%)$} \\
\hline & Antes & Depois & Antes & Depois & Antes & Depois & Antes & Depois \\
\hline $0 \mathrm{~cm}-0 \mathrm{~kg} \mathrm{ha}^{-1} \mathrm{de} \mathrm{N}$ & 6,2 & $6,2^{\mathrm{ns}}$ & 9,5 & $9,7 \mathrm{~ns}$ & 74 & $72 *$ & 6,0 & $5,8^{\mathrm{ns}}$ \\
\hline $1 \mathrm{~cm}-47 \mathrm{~kg} \mathrm{ha}^{-1} \mathrm{de} \mathrm{N}$ & 6,2 & $6,3^{\mathrm{ns}}$ & 9,7 & $9,6^{\mathrm{ns}}$ & 75 & $72 *$ & 5,7 & $6,2 \mathrm{~ns}$ \\
\hline $2 \mathrm{~cm}-94 \mathrm{~kg} \mathrm{ha}^{-1} \mathrm{de} \mathrm{N}$ & 6,2 & $6,4^{\mathrm{ns}}$ & 9,5 & $9,4 \mathrm{~ns}$ & 74 & $72 \mathrm{~ns}$ & 5,9 & $6,0^{\mathrm{ns}}$ \\
\hline $3 \mathrm{~cm}-141 \mathrm{~kg} \mathrm{ha}^{-1} \mathrm{de} \mathrm{N}$ & 6,2 & $6,3 *$ & 9,3 & $10,0 *$ & 74 & $73^{\mathrm{ns}}$ & 5,8 & $6,0^{\mathrm{ns}}$ \\
\hline \multirow[t]{2}{*}{$4 \mathrm{~cm}-188 \mathrm{~kg} \mathrm{ha}^{-1} \mathrm{de} \mathrm{N}$} & 6,2 & $6,4 *$ & 9,6 & $10,2 *$ & 74 & $73^{\mathrm{ns}}$ & 5,8 & $5,7^{\mathrm{ns}}$ \\
\hline & \multicolumn{8}{|c|}{ (B) Biomassa de mamona } \\
\hline \multirow[t]{3}{*}{ Espessura - aporte de $\mathrm{N}$} & \multicolumn{2}{|c|}{$\mathrm{pH}$} & \multicolumn{2}{|c|}{ CTC } & \multicolumn{2}{|c|}{$\mathrm{V}$} & \multicolumn{2}{|c|}{ MO } \\
\hline & \multicolumn{2}{|c|}{ (água $1: 2,5$ ) } & \multicolumn{2}{|c|}{$\left(\mathrm{cmol}_{\mathrm{c}} \mathrm{dm}^{-3}\right)$} & \multicolumn{4}{|c|}{$(\%)$} \\
\hline & Antes & Depois & Antes & Depois & Antes & Depois & Antes & Depois \\
\hline $0 \mathrm{~cm}-0 \mathrm{~kg} \mathrm{ha}^{-1} \mathrm{de} \mathrm{N}$ & 6,3 & $6,3^{\mathrm{ns}}$ & 9,9 & $9,6^{\mathrm{ns}}$ & 77 & $74 *$ & 6,4 & $6,0^{\mathrm{ns}}$ \\
\hline $1 \mathrm{~cm}-43 \mathrm{~kg} \mathrm{ha}^{-1}$ de $\mathrm{N}$ & 6,3 & $6,3^{\mathrm{ns}}$ & 9,6 & $9,9^{\mathrm{ns}}$ & 76 & $74 *$ & 5,7 & $5,2 \mathrm{~ns}$ \\
\hline $2 \mathrm{~cm}-86 \mathrm{~kg} \mathrm{ha}^{-1} \mathrm{de} \mathrm{N}$ & 6,3 & $6,5 *$ & 9,7 & $10,6 *$ & 76 & $77^{\mathrm{ns}}$ & 5,7 & $5,3 \mathrm{~ns}$ \\
\hline $3 \mathrm{~cm}-129 \mathrm{~kg} \mathrm{ha}^{-1} \mathrm{de} \mathrm{N}$ & 6,3 & $6,5 *$ & 9,9 & $10,9 *$ & 77 & $78^{\mathrm{ns}}$ & 6,0 & $6,3^{\mathrm{ns}}$ \\
\hline $4 \mathrm{~cm}-172 \mathrm{~kg} \mathrm{ha}^{-1} \mathrm{de} \mathrm{N}$ & 6,3 & $6,5 *$ & 9,8 & $11,7 *$ & 76 & $77^{\mathrm{ns}}$ & 5,3 & $5,5 \mathrm{~ns}$ \\
\hline
\end{tabular}

${ }^{1 \text { ns }}$ não significativo e $*$ significativo a $5 \%$ pelo teste ' $t$ ', comparando antes e depois para cada variável.

Tabela 1 - Teores de fósforo $(\mathrm{P})$, potássio $(\mathrm{K})$, cálcio $(\mathrm{Ca})$ e magnésio $(\mathrm{Mg})$ no solo, antes e 28 dias após a adubação de cobertura com biomassa de leucena (A) e mamona (B)1

\begin{tabular}{|c|c|c|c|c|c|c|c|c|}
\hline \multirow{4}{*}{ Espessura - aporte de $\mathrm{N}$} & \multicolumn{8}{|c|}{ (A) Biomassa de leucena } \\
\hline & \multicolumn{2}{|c|}{$\mathrm{P}$} & \multicolumn{2}{|c|}{ K } & \multicolumn{2}{|c|}{$\mathrm{Ca}$} & \multicolumn{2}{|c|}{$\mathrm{Mg}$} \\
\hline & \multicolumn{4}{|c|}{$\left(\mathrm{mg} \mathrm{dm}^{-3}\right)$} & \multicolumn{4}{|c|}{$\left(\mathrm{cmolc} \mathrm{dm}^{-3}\right)$} \\
\hline & Antes & Depois & Antes & Depois & Antes & Depois & Antes & Depois \\
\hline $0 \mathrm{~cm}-0 \mathrm{~kg}$ ha- $1 \mathrm{de} \mathrm{N}$ & 129 & $114 *$ & 455 & $425 \mathrm{~ns}$ & 4.7 & $4.7 \mathrm{~ns}$ & 1.2 & $1.1 *$ \\
\hline $1 \mathrm{~cm}-47 \mathrm{~kg}$ ha- $1 \mathrm{de} \mathrm{N}$ & 126 & $110 *$ & 460 & $465 \mathrm{~ns}$ & 4.8 & $4.7 \mathrm{~ns}$ & 1.2 & $1.1 *$ \\
\hline $2 \mathrm{~cm}-94 \mathrm{~kg}$ ha-1 de $\mathrm{N}$ & 124 & $114 *$ & 451 & $474 \mathrm{~ns}$ & 4.7 & $4.6 \mathrm{~ns}$ & 1.2 & $1.1 *$ \\
\hline $3 \mathrm{~cm}-141 \mathrm{~kg}$ ha- $1 \mathrm{de} \mathrm{N}$ & 128 & $114 *$ & 454 & $608 *$ & 4.6 & $4.7 \mathrm{~ns}$ & 1.2 & $1.2 *$ \\
\hline $4 \mathrm{~cm}-188 \mathrm{~kg}$ ha- $1 \mathrm{de} \mathrm{N}$ & 124 & $115 *$ & 465 & $680 *$ & 4.7 & $4.6 \mathrm{~ns}$ & 1.2 & $1.1 *$ \\
\hline
\end{tabular}

(B) Biomassa de mamona

\begin{tabular}{|c|c|c|c|c|c|c|c|c|}
\hline \multirow{4}{*}{ Espessura - aporte de N } & \multirow{2}{*}{\multicolumn{4}{|c|}{ K }} & \multirow{2}{*}{\multicolumn{2}{|c|}{$\mathrm{Ca}$}} & \multirow{2}{*}{\multicolumn{2}{|c|}{$\mathrm{Mg}$}} \\
\hline & & & & & & & & \\
\hline & \multicolumn{4}{|c|}{$\left(\mathrm{mg} \mathrm{dm}^{-3}\right)$} & \multicolumn{4}{|c|}{$\left(\mathrm{cmolc} \mathrm{dm}^{-3}\right)$} \\
\hline & Antes & Depois & Antes & Depois & Antes & Depois & Antes & Depois \\
\hline $0 \mathrm{~cm}-0 \mathrm{~kg}$ ha- $1 \mathrm{de} \mathrm{N}$ & 133 & $115 *$ & 605 & $602 \mathrm{~ns}$ & 4.8 & $4.5 \mathrm{~ns}$ & 1.3 & $1.1 *$ \\
\hline $1 \mathrm{~cm}-43 \mathrm{~kg}$ ha- $1 \mathrm{de} \mathrm{N}$ & 127 & $110 *$ & 496 & $713 \mathrm{~ns}$ & 4.8 & $4.4 \mathrm{~ns}$ & 1.2 & $1.1 \mathrm{~ns}$ \\
\hline $2 \mathrm{~cm}-86 \mathrm{~kg}$ ha-1 de $\mathrm{N}$ & 132 & $116 *$ & 518 & $1045 *$ & 4.9 & $4.4 \mathrm{~ns}$ & 1.3 & $1.2 *$ \\
\hline $3 \mathrm{~cm}-129 \mathrm{~kg}$ ha- $1 \mathrm{de} \mathrm{N}$ & 137 & $122 *$ & 532 & $1003 *$ & 5.0 & $4.7 \mathrm{~ns}$ & 1.3 & $1.3 \mathrm{~ns}$ \\
\hline $4 \mathrm{~cm}-172 \mathrm{~kg}$ ha- $1 \mathrm{de} \mathrm{N}$ & 126 & $112 *$ & 465 & $1142 *$ & 5.0 & $5.1 \mathrm{~ns}$ & 1.2 & $1.1 *$ \\
\hline
\end{tabular}

${ }^{1 \text { ns }}$ não significativo e * significativo a $5 \%$ pelo teste ' $t$ ', comparando antes e depois para cada variável. 
maior efeito da mamona se justifica pela sua maior composição em K (2,2\% na mamona, contra $2,0 \%$ na leucena). Os teores de cálcio no solo não foram influenciados pelo aporte das biomassas e os teores de magnésio sofreram redução.

As espessuras das camadas não apresentaram ajustes significativos aos modelos de regressão para os atributos químicos do solo, à exceção do teor de potássio, que foi favorecido com o aumento das quantidades de biomassas de leucena e mamona aplicadas, apresentando ajustes lineares significativos, conforme mostrado na Figura $2 \mathrm{~A} \mathrm{e}$ $2 \mathrm{~B}$, respectivamente. Pela maior inclinação da reta, verifica-se aporte de $\mathrm{K}$ foi mais intenso para a mamona, provavelmente, devido apresentar maior teor de $\mathrm{K}$ nos seus tecidos.
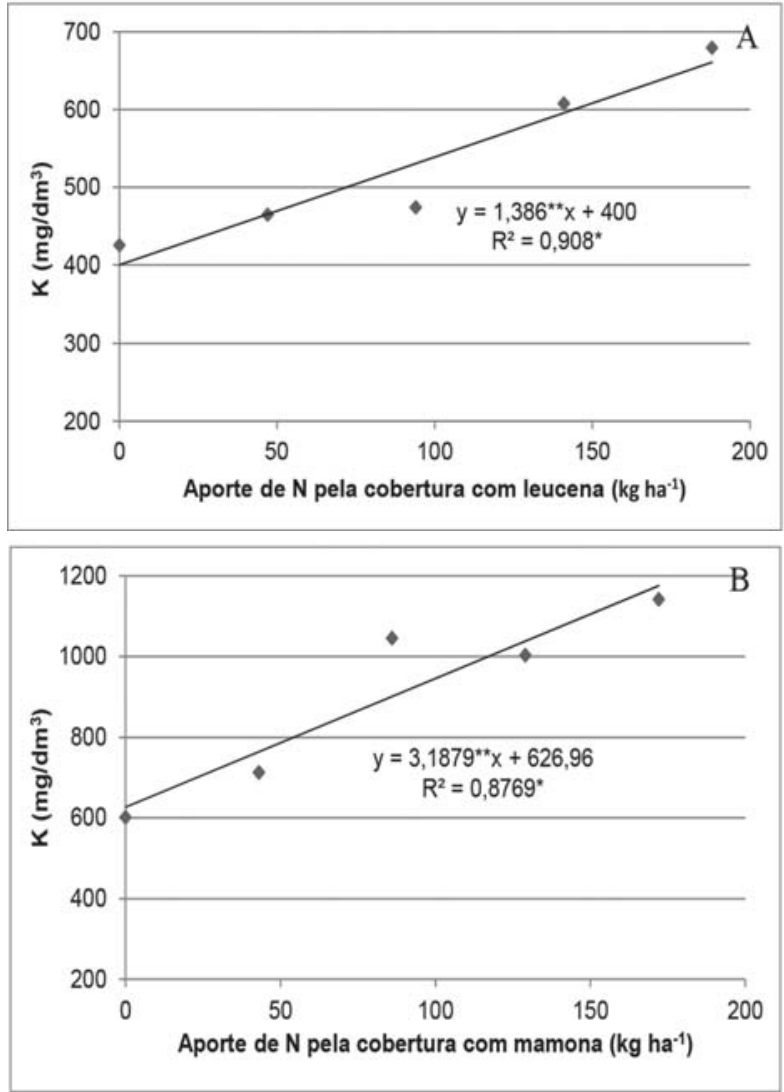

Figura 2 - Teores de potássio no solo em função do aporte de $\mathrm{N}$ pela adubação de cobertura com biomassa de leucena (A) e mamona (B), 28 dias após a aplicação.

\section{CONCLUSÃO}

O uso de biomassa verde triturada de leucena e mamona como adubos de cobertura proporcionaram efeitos positivos sobre o desenvolvimento inicial das plantas de repolho, especialmente nas maiores espessuras, com efeitos mais expressivos ocorrendo no final do período avaliado, aos 28 dias após a adubação.

Não foram verificados efeitos significativos sobre os atributos do solo pH, CTC, V, MO, P, Ca e Mg para as diferentes espessuras de aplicação das biomassas de leucena e mamona, à exceção do teor de potássio, que foi favorecido com o aumento das quantidades de biomassas aplicadas.

Tanto a biomassa de leucena como de mamona, apresentam potencial de uso como adubação em cobertura em cultivo orgânico de repolho.

\section{LITERATURA CITADA}

AGUYOH, J.N.; AUDI, W.; SAIDI, M. et al. Growth, yields and quality response of watermelon (Citrullus lanatus (Thumb) Mansf. \& nakai) cv. Crimson Sweet) subjected to different levels of tithonia manure. International Journal of Science and Nature, v.1, n.1, p.7-11, 2010.

AITA, C.; GIACOMINI, S.J. Decomposição e liberação de nitrogênio de resíduos culturais de plantas de cobertura de solo solteiras e consorciadas. Revista Brasileira de Ciência do Solo, v.27, p.601-612, 2003.

BAGGIO, A.J.; SOARES, A.O.

Comportamento do morango (Fragaria $x$ ananassa Duch.) sob adubação verde com Timbó (Ateleia glazioveana Baillon). Colombo, PR: EMBRAPA Florestas, 2002. 4p.

BARRETO, A.C.; FERNANDES, M.F. Cultivo de Gliricidia sepium e Leucaena leucocephala em alamedas visando a melhoria dos solos dos tabuleiros costeiros. Pesquisa Agropecuária Brasileira, v.36, n.10, p.1287-1293, 2001.

EKBLADH, G.; WITTER, E.; ERICSSON, T. Ontogenetic decline in the nitrogen concentration of field grown white cabbage - Relation to growth components. Scientia Horticulturae, v.112, p.149-155, 2007. 
EMBRAPA - Empresa Brasileira de Pesquisa Agropecuária. Manual de métodos de análise de solo. Rio de Janeiro: Ministério da Agricultura e do Abastecimento, 1997. 212p. 2ed.

FERREIRA, W.R.; RANAL, M.A.; FILGUEIRA, F.A.R. Fertilizantes e espaçamento entre plantas na produtividade da couve-da-malásia.

Horticultura Brasileira, v.20, p.635-640. 2002.

JAMA, B.; PALM, C.A.; BURESH, R.J. et al. Tithonia diversifolia as a green manure for soil fertility improvement in western Kenya: A review. Agroforestry Systems, v.49, n.2, p.221-221, 2000 .

MARSCHNER, H. Mineral nutrition of higher plants. London: Academic Press, 1995. 889p.
MOREIRA, M.A.; VIDIGAL, S.M.; SEDIYAMA, M.A.N. et al. Crescimento e produção de repolho em função de doses de nitrogênio.

Horticultura Brasileira, v.29, n.1, p.117$121,2011$.

OLIVEIRA, F.F.; GUERRA, J.G.M.; ALMEIDA, D.L.A. et al. Avaliação de coberturas mortas em cultura de alface sob manejo orgânico.

Horticultura Brasileira, v.26, p.216-220, 2008.

RIBEIRO JÚNIOR J.I.; MELO, A.L.P. Guia prático para utilização do SAEG. Viçosa: Folha Editora, 2009. 288p.

YEOMANS, J.C.; BREMNER, J.M. A rapid and precise method for routine determination of organic carbon in soil. Communications in Soil Science and Plant Analysis, v.19, n.13, p.1467-1476, 1988 . 